\title{
Novel neurotherapeutics in psychiatry: use and rationale of transcranial direct current stimulation in major depressive disorder
}

\section{Novas neuroterapêuticas em psiquiatria: racional e uso da estimulação transcraniana por corrente contínua no transtorno depressivo maior}

\author{
Adriano H. Moffa ${ }^{1,2}$, Leandro Valiengo ${ }^{1,2}$, Pedro Shiozawa33, André Russowsky Brunoni ${ }^{1,2}$ \\ 1 Service of Interdisciplinary Neuromodulation and Laboratory of Neurosciences (LIM-27), Department and Institute of Psychiatry, University of São Paulo (USP). \\ 2 Interdisciplinary Center for Applied Neuromodulation, University Hospital, USP. \\ 3 Laboratory of Clinical Neuromodulation, Santa Casa Medical School, São Paulo.
}

Received: $12 / 10 / 2013$ - Accepted: $12 / 18 / 2013$

\begin{abstract}
Background: Transcranial direct current stimulation (tDCS) is a novel non-pharmacological intervention being investigated for the treatment of major depressive disorder (MDD). Objective: To perform an updated review of tDCS for MDD. Method: Systematic review in Medline/PubMed and other databases of all clinical studies evaluating the clinical efficacy of tDCS in MDD, from the first date available to December/2013. Results: Out of 55 articles, 24 were included, being 6 open-label studies; 8 randomized, double-blind, sham-controlled trials; 2 follow-up studies; 2 meta-analyses and 6 case reports. We observed an improvement of $20-40 \%$ in depressive symptoms, being slightly better in open studies. Five randomized clinical trials displayed positive results. The meta-analyses presented mixed results; although none included the study of Brunoni et al. (2013) that represents almost 50\% of the evaluated sample. Open-label studies and case reports also investigated tDCS in bipolar depression, post-stroke depression and employed different parameters of stimulation. Discussion: TDCS is a novel, promising treatment for MDD. Definite evidence from large, ongoing clinical trials will be available in the next years.
\end{abstract}

Moffa AH, et al. / Rev Psiq Clín. 2014;41(1):15-20

Keywords: Transcranial direct current stimulation, major depressive disorder, systematic review, non invasive neuromodulation, interventional psychiatry, neurotherapeutics.

\section{Resumo}

Contexto: A estimulação transcraniana por corrente contínua (ETCC) é uma nova intervenção não farmacológica investigada como tratamento no transtorno depressivo maior (TDM). Objetivo: Apresentar uma revisão atualizada da ETCC no TDM. Método: Revisão sistemática no banco de dados Medline/ PubMed e outros de todos os estudos clínicos publicados avaliando a eficácia da ETCC no TDM, da primeira data disponível a dezembro/2013. Resultados: De 55 artigos, 24 foram incluídos, sendo 6 estudos abertos; 8 ensaios clínicos randomizados, duplo-cego, placebo controlados; 2 estudos de seguimento; 2 metanálises e 6 relatos de caso. Observa-se uma melhora de 20-40\% nos sintomas depressivos, sendo ligeiramente maior nos estudos abertos. Entre os ensaios controlados, 5 demonstraram eficácia da técnica. As metanálises divergiram quanto aos resultados, mostrando presença e ausência de eficácia e ausência da ETCC. Porém, nenhuma incluiu o estudo de Brunoni et al. (2013), que representa quase 50\% da população estudada. Estudos abertos e relatos de caso também investigaram o uso da ETCC na depressão bipolar, na depressão pós-AVC e usaram variações nos parâmetros de estimulação. Conclusões: A ETCC é uma técnica promissora no tratamento da TDM. Evidências definitivas devem estar disponíveis nos próximos anos, com a divulgação de resultados de grandes ensaios clínicos em andamento.

Moffa AH, et al. / Rev Psiq Clín. 2014;41(1):15-20

Palavras-chave: Estimulação transcraniana por corrente contínua, transtorno depressivo maior, revisão sistemática, neuromodulação não invasiva, psiquiatria intervencionista, neuroterapêuticas.

\section{Introduction}

The use of electricity as a clinical treatment is not novel in medical literature. For instance, there are reports of using the "torpedo-fish" to treat pain since the Ancient times ${ }^{1}$. Nonetheless, the controlled use of electric currents for medical disorders only begun in the $18^{\text {th }}$ century, with the development of the voltaic pile - even though, the application of electric currents over one's scalp was still erratic and poorly executed ${ }^{2}$. In 1960s and 1970s there are reports of a method of non-invasive brain stimulation named "brain polarization", quite similar to modern transcranial direct current stimulation (tDCS), which could enhance mood and alertness in healthy volunteers ${ }^{3}$ and treat depression ${ }^{4,5}$. Later on, this method was largely abandoned, possibly due to the advancement of psychopharmacology ${ }^{6}$ and the social stigma of electroconvulsive therapy (ECT) that hindered the development of other forms of non-invasive brain stimulation.
In fact, tDCS was only reappraised as a neuromodulatory tool in the turn of the $21^{\text {st }}$ century, with the seminal works of Priori et al. 7 and Nitsche and Paulus ${ }^{8}$ who showed that the induction of a weak, direct current through electrodes placed over the scalp could increase (anode) and decrease (cathode) cortical excitability beyond the period of stimulation. Notwithstanding its exact mechanisms of action being still elusive, $\mathrm{tDCS}$ probably operates by inducing small changes $(<1 \mathrm{mV})$ in the membrane potential ${ }^{9}$, thus acting in the frequency of spike timing and modifying net cortical excitability ${ }^{10}$. The mechanisms of action of $\mathrm{tDCS}$ occur also at the synaptic level. For instance, glutamate antagonists abolish tDCS after-effects, while NMDA-agonists enhance them ${ }^{11}$.

Moreover, tDCS presents a low rate of adverse effects and is a safe technique when used according to the standard procedures. In a recent systematic review of clinical studies, our group ${ }^{12}$ observed the lack of serious adverse effects associated with tDCS; with the excep- 
tion of one case of skin burn ${ }^{13}$. In an animal study of safety, Liebetanz et al. ${ }^{14}$ showed, in an animal study of safety, that cathodal-induced brain lesions only occurred when the stimulation intensities almost one hundred times higher than used in clinical studies. In addition, tDCS does not adversely affect brain and heart activity, respectively measured using EEG and EKG records ${ }^{15-17}$. In fact, the only adverse effect particularly associated with tDCS is skin redness ${ }^{18}-$ even though, this effect is mild and does not seem to compromise blinding in sham-controlled tDCS trials ${ }^{19}$, which consist in turning off the device after $<30-60$ seconds of stimulation, remaining turned off until the end of the session ${ }^{20}$. Finally, tDCS is, compared to repetitive transcranial magnetic stimulation (rTMS), a relatively cheaper, easier to use, more portable technique with even less adverse effects.

Such appealing characteristics motivated the research of using tDCS for the treatment of neuropsychiatric disorders (for a review $\mathrm{see}^{21}$, and, among them, tDCS has been showing particularly positive results in major depression, with the anode positioned over the left dorsolateral prefrontal cortex (DLPFC) and the cathode over the right DLPFC, the right supraorbital area or in an extra-cephalic position ${ }^{2}$. The rationale for using this montage in depression rests on: (1) the prefrontal asymmetry theory of depression, with relative hypoactivity over the left and relative hyperactivity over the right 22,23 ; (2) the improvement in working memory and affective processing observed after one-single tDCS session in depressed patients ${ }^{24-26}$; (3) the top-down, neuromodulatory effects of tDCS, possibly reversing the imbalance between hypoactive cortical areas and hyperactive subcortical areas ${ }^{23,25}$, (4) the clinical effects observed in rTMS using either rapid, facilitatory stimulation over the left DLPFC and slow, inhibitory stimulation over the right DLPFC ${ }^{27,28}$.

The purpose of this review is, therefore, to summarize the findings of all clinical studies using tDCS in depression hitherto, as well as to discuss future challenges and perspectives for using tDCS as a novel intervention in the therapeutic arsenal of major depression.

\section{Methods}

We performed a literature review in PubMed/Medline, Scopus and Web of Science databases from English-written articles from 1998 to December 2013. The key search terms in PubMed were: "transcranial direct current stimulation" OR "transcranial electric stimulation" AND "depressive disorder". We did not include editorials or articles reporting duplicated data. For the purposes of this review, meta-analyses evaluating the efficacy of tDCS in depression were also included.

\section{Results}

Out of 55 articles, 23 fulfilled our eligibility criteria. According to the study design, retrieved articles could be further classified in five types, as described below:

\section{Open-label studies}

Rigonatti et al. ${ }^{29}$ compared the clinical effects of active prefrontal tDCS $v s$. a six-week treatment protocol with $20 \mathrm{mg} /$ day fluoxetine, finding that the effects of both therapies were similar. Ferrucci et al. ${ }^{30}$ used tDCS in 14 patients with severe depression using $2 \mathrm{~mA}$ per day, twice a day for 5 consecutive days, demonstrating an improvement of about $30 \%$ on depressive symptoms. In another study, Ferrucci et al. ${ }^{31}$ evaluated 32 patients, finding that $\mathrm{tDCS}$ improvement was bolder in severe depression (50\%) than those in mild/moderate depression (10\%). Brunoni et al. ${ }^{32}$ used anodal tDCS over the left DLPFC in 31 patients (14 with bipolar and 17 with unipolar depression). Depressive symptoms in both study groups improved immediately after the $5^{\text {th }}$ session. The beneficial effect persisted after one week and one month. Another recent open study ${ }^{33}$ demonstrated the efficacy of tDCS in 23 patients with refractory depression, with a mean reduction in symptoms of $25 \%$. Martin et al. ${ }^{34}$ performed tDCS sessions consecutively for 20 days, with $2 \mathrm{~mA}$ for 20 minutes, in 11 patients with depression. In this open study, which placed the cathode on the right deltoid muscle, there was also a significant reduction in symptoms of about $44 \%$. Finally, in the largest open-label sample to date, Brunoni et al. 35 , in 82 patients with unipolar and bipolar depression, found that five days of twice daily tDCS significantly improved depression symptoms. This study also showed that the effects of tDCS are enhanced when associated with antidepressants and decreased with benzodiazepines (Table 1).

\section{Randomized, sham-controlled trials}

Fregni et al. ${ }^{36}$ in the first sham-controlled, randomized clinical trial, found a significant decrease in the Hamilton Depression Rating Scale and Beck Depression Inventory after 5 days of active stimulation with $1 \mathrm{~mA}$ for $20 \mathrm{~min}$ once daily in 10 patients, with a mean reduction in depression scores of $60-70 \%$ for active tDCS group relative to baseline. Similar results were demonstrated in a further study in antidepressant-free patients with recurrent major depressive episodes after 5 days of active tDCS stimulation ${ }^{37}$ with 18 patients. Boggio et al..$^{38}$ recruited 40 patients with moderate to severe depression, evaluating depression improvement after 30 days of stimulation (patients received $10 \mathrm{tDCS}$ sessions). Only prefrontal tDCS reduced depressive symptoms significantly.

After these positive results, three other studies reported negative findings. Loo et al. ${ }^{39}$ recruited 40 patients to receive active $v s$. sham tDCS and did not find significant differences between these groups. However, treatment was provided for only five treatment sessions, 3 days per week. This study also did not exclude patients with personality disorders. Palm et al..$^{40}$ recruited 22 patients with depression and randomized them to receive $1 \mathrm{~mA}$ stimulation, $2 \mathrm{~mA}$ stimulation or sham tDCS in a cross-over design. Active and placebo tDCS was applied for 2 weeks, but no differences in depression improvement were found. Finally, Blumberger et al. ${ }^{41}$ did not find significant differences between active $v s$. sham tDCS in a tertiary sample of 24 refractory patients. All these studies acknowledged methodological limitations (notably small sample sizes) that could have undermined the efficacy of tDCS.

In fact, two larger, recent tDCS trials observed that tDCS was an effective treatment for depression. Loo et al. ${ }^{42}$ randomized 64 patients to receive active or sham tDCS ( $2 \mathrm{~mA}, 15$ sessions over 3 weeks), followed by a 3-week open-label active treatment phase. Mood and neuropsychological effects were assessed. There was significantly greater improvement in mood after active than sham treatment. Attention and working memory improved after a single session of active but not sham tDCS. There was no decline in neuropsychological functioning after 3-6 weeks of active stimulation. Finally, our group ${ }^{43}$ enrolled 120 antidepressant-free patients with moderate and severe depression who were randomized in four arms (2x2 design): sham tDCS and placebo pill, sham tDCS and sertraline, active tDCS and placebo pill and active tDCS and sertraline (the study name was Sertraline vs. Electric Current Therapy to Treat Depression Clinical Trial - SELECT-TDCS; its design is described in ${ }^{44}$ ). The tDCS parameters were $2 \mathrm{~mA}$ per 30 minutes/day, for 2 weeks and 2 extra tDCS sessions every other week until week 6 (study endpoint); the dose of sertraline was fixed $(50 \mathrm{mg} /$ day $)$. Our main findings were that: (1) the combined tDCS/sertraline was significantly more effective than in the other treatment groups in reducing depressive symptoms; (2) tDCS and sertraline efficacy did not differ; (3) active tDCS as a monotherapy was also more effecitve than the placebo group. Of note, we also found (1) no decline in cognitive improvement after tDCS or sertraline treatment; (2) 5 cases of hypomanic/ manic episodes in the combined treatment group $v s$. one case in tDCS-only, one case in sertraline-only and no cases in the placebo arm (although this difference was not statistically significant); (3) use of benzodiazepines and treatment-resistant depression were both predictors of lower response; (4) treatment was well-tolerated with mild adverse effects, which were of similar frequency in both arms, except for skin redness that was more prevalent in the active group. Biological markers were also evaluated (some of them are discussed below) (Table 2). 
Table 1. Open-label tDCS studies

\begin{tabular}{|c|c|c|c|c|c|c|}
\hline Author & Sample (n) & Anode & Cathode & Intensity $\left(\mathrm{A} / \mathrm{m}^{2}\right)$ & Number of sessions & $\begin{array}{l}\text { Depression } \\
\text { improvement }\end{array}$ \\
\hline Rigonatti et al., $2008^{29}$ & 42 & F3 & R SO & 0.57 & 10 (1x/day) & $36.20 \%$ \\
\hline Ferrucci et al., 200930 & 14 & F3 & F4 & 0.57 & 10 (2x/day) & $32.1 \%$ \\
\hline Ferrucci et al., 200931 & 32 & F3 & F4 & 0.57 & 10 (2x/day) & $27.70 \%$ \\
\hline Brunoni et al., $2011^{32}$ & 31 & F3 & F4 & 0.57 & 10 (2x/day) & $45.2 \%$ \\
\hline Martin et al., $2011^{34}$ & 11 & F3 & R arm & 0.57 & 20 (1x/day) & $42.80 \%$ \\
\hline Dell'Osso et al., $2012^{33}$ & 23 & F3 & F4 & 0.57 & 10 (2x/day) & $31.30 \%$ \\
\hline Brunoni et al., 201335 & 82 & F3 & F4 & 0.57 & 10 (2x/day) & $18 \%$ \\
\hline
\end{tabular}

F3: left dorsolateral prefrontal cortex; F4: right dorsolateral prefrontal cortex; $R$ arm: right arm; R SO: right supraorbital area; tDCS: transcranial direct current stimulation. Depression improvement is the score change in from baseline to endpoint, for each study.

\section{Follow-up studies}

Two studies evaluated the efficacy of tDCS in the maintenance phase of the depressive episode. We ${ }^{44}$ recruited 42 patients who were tDCS responders from the SELECT-TDCS trial and performed tDCS sessions every other week for 3 months and then every month for 3 additional months (tDCS sessions were interrupted earlier in case of relapse, characterizing failure treatment). In this follow-up study, we observed that treatment-resistant depression was significantly associated with an increased relapse rate (over $80 \%$ in 6 months). On the other hand, $>80 \%$ non-refractory patients sustained clinical response for at least 6 months. In this trial, the overall relapse rate in 6 months was around 50\%, with most relapses occurring in the first 3 months. Another group ${ }^{45}$ also followed patients previously recruited to a randomized clinical trial $(n=26)$ and performed weekly $\mathrm{tDCS}$ sessions for 3 months, followed by tDCS sessions every other week in the remaining 3 months. Similarly to our findings, a relapse rate around 50\% in 6 months was observed. However, most relapses occurred after the 3 initial months, when tDCS sessions were spaced. Therefore, although the evidence is very preliminary, this trial suggests that an intensive continuation treatment (at least once a week $\mathrm{tDCS}$ session) during early follow-up might be recommended to sustain clinical improvement.

\section{Case reports}

The available case reports for tDCS in depression fall into three scenarios: (1) report of emergent hypomanic/manic symptoms following tDCS $46-49$; (2) description of tDCS use in a specific type of depression (post-stroke depression) $)^{50}$ and (3) evaluation of clinical symptoms and EEG findings in a patients with treatment-resistant depression $^{51}$ (Table 3).

\section{Meta-analyses}

The two published meta-analyses for tDCS in depression showed disparate results - interestingly, these meta-analyses evaluated the same randomized clinical trials described above (except for our factorial trial that was not published yet) as they used different outcome measures - i.e., Kalu et al. 52 employed continuous outcomes (depression improvement) and Berlim et al. ${ }^{53}$ dichotomic measures (response and remission) for estimating the effect size of the intervention. In an updated meta-analysis including data from our recent clinical trial, we found that active $v s$. sham tDCS was more effective using both continuous and categorical outcomes (Shiozawa et al., study under review), with the effect being small to moderate.

Table 2. Randomized, controlled tDCS trials

\begin{tabular}{|c|c|c|c|c|c|c|}
\hline Author & Sample (n) & Anode & Cathode & Intensity $\left(\mathrm{A} / \mathrm{m}^{2}\right)$ & Number of sessions & $\begin{array}{l}\text { Outcome (score } \\
\text { improvement) }\end{array}$ \\
\hline Fregni et al., 200636 & 10 & F3 & R SO & 0.28 & 5 (every other day) & $60 \%$ \\
\hline Fregni et al., 200637 & 18 & F3 & R SO & 0.28 & 5 (every other day) & $58.50 \%$ \\
\hline Boggio et al., $2008^{38}$ & 40 & F3 & F4 & 0.28 & 10 (1x/day) & $40.40 \%$ \\
\hline Loo et al., $2010^{39}$ & 40 & F3 & R SO & 0.28 & 5 (every other day) & $19.5 \%$ \\
\hline Palm et al., $2011^{40}$ & 22 & F3 & R SO & $0.28 / 0.57$ & 10 (1x/day) & $14.6 \% / 16.7 \%$ \\
\hline Blumberger et al., 201241 & 24 & F3 & F4 & 0.57 & 15 (1x/day) & $24.50 \%$ \\
\hline Loo et al., $2012^{42}$ & 64 & F3 & R SO & 0.57 & 15 (1x/day) & $28.40 \%$ \\
\hline Brunoni et al., $2013^{43}$ & 120 & F3 & $\mathrm{F} 4$ & 0.8 & 10 (1x/day) & $29.8 \% / 55.6 \%{ }^{*}$ \\
\hline
\end{tabular}

F3: left dorsolateral prefrontal cortex; F4: right dorsolateral prefrontal cortex; R arm: right arm; R SO: right supraorbital area; tDCS: transcranial direct current stimulation. Depression improvement is the score change in from baseline to endpoint, for each study. ${ }^{*}$ Represents depression improvement in the active tDCS/placebo-pill and active tDCS/sertraline arms, respectively.

Table 3. TDCS case reports

\begin{tabular}{|c|c|c|c|c|c|}
\hline Author & Sample (n) & Anode & Cathode & Intensity $\left(\mathrm{A} / \mathrm{m}^{2}\right)$ & Number of sessions \\
\hline Palm et al., 200951 & 1 & F3 & R SO & 0.28 & 16 \\
\hline Baccaro et al., $2010^{46}$ & 1 & F3 & $\mathrm{F} 4$ & 0.57 & 5 \\
\hline Arul-Anandam et al., $2010^{48}$ & 1 & F3 & R SO & 0.28 & 5 \\
\hline Brunoni et al., 201147 & 1 & F3 & F4 & 0.57 & 5 \\
\hline Bueno et al., 201150 & 1 & F3 & $\mathrm{F} 4$ & 0.57 & 10 \\
\hline Galvez et al., $2011^{49}$ & 1 & F3 & R arm & 0.57 & 14 \\
\hline
\end{tabular}

F3: left dorsolateral prefrontal cortex; F4: right dorsolateral prefrontal cortex; $\mathrm{R}$ arm: right arm; R SO: right supraorbital area; tDCS: transcranial direct current stimulation. Depression improvement is the score change in from baseline to endpoint, for each study. 


\section{Discussion}

We reviewed 24 clinical studies (from case reports to randomized clinical trials) and two meta-analyses that evaluated the clinical efficacy of tDCS in major depression. The clinical improvement, considering changes in depression scores, ranged from $20-40 \%$ according to number of tDCS applications, sample characteristics (refractoriness, severity) and study design, with open-label trials showing discretely better results than the active arms of sham-controlled trials. Such improvement is in the same range of antidepressant drug treatment ${ }^{54}$ and, in fact, two studies that directly compared tDCS $v s$. fluoxetine ${ }^{29}$ and sertraline ${ }^{43}$ found similar improvement rates in the pharmacological and non-pharmacological arms. This could suggest that tDCS might be a substitute for pharmacotherapy when its use is hindered, for instance, due to medical conditions ${ }^{55}$. The advantages of substituting medicines to tDCS are that the latter is virtually absent of side effects and pharmacological interactions. On the other hand, the necessity of daily $\mathrm{tDCS}$ sessions requires that the patients daily return to the service, undermining adhesion. In this context, the development of portable, "home-use" tDCS devices could help in this issue, as the number of visits to the clinical center would be dramatically reduced.

Moreover, other reviewed studies evaluated the role of tDCS as an augmentation strategy for pharmacotherapy, showing that the combined therapy of tDCS with antidepressant drugs was associated with superior improvement and, interestingly, that tDCS combined with benzodiazepine drugs presented decreased efficacy ${ }^{35,43}$. These findings might be explained by neurophysiological studies in healthy volunteers that evaluated motor evoked potential changes after taking a pharmacological agent (or placebo). Using this design, Nitsche et al. ${ }^{56}$ observed that the effects of anodal tDCS are greatly enhanced by the SSRI citalopram, and also that the inhibitory effects of cathodal tDCS changes to excitatory after citalopram. In fact, in ancillary SELECT-TDCS studies we found that the 5-HTTLPR (serotonin transporter) polymorphism impacts on $\mathrm{tDCS}$ response $\mathrm{e}^{57}$ and that tDCS combined to sertraline was the only treatment effective for the core symptoms of depression (depressed mood and anhedonia) ${ }^{58}$. Therefore, although the mechanistic foundations for the greater effects of the combined therapy remain elusive, one hypothesis is that these interventions have synergistic effects, one augmenting the other.

Another critical and unclear point is the optimal treatment protocol during the maintenance phase. Only two follow-up studies were carried out hitherto ${ }^{44,45}$ with relatively poor results, with a relapse rate of around $50 \%$ in six months. We propose that the same strategies under research for rTMS could be employed here, namely more frequent stimulation sessions and use of antidepressant drugs during the maintenance phase. Future studies should also explore whether patients who responded to tDCS and further relapse would again achieve clinical response after another $\mathrm{tDCS}$ trial.

Finally, it should be underscored that not all clinical trials yielded positive results and one meta-analysis failed to show superiority from active tDCS to sham treatment. Some reasons for these mixed findings include relatively small sample sizes, disparate treatment modalities (including number of sessions, cathode positioning, duration and intensity of the sessions etc.) and different depression characteristics (regarding refractoriness, severity, mean age, unipolar $v s$. bipolar depression and concomitant use of pharmacotherapy) in the sample. In our updated meta-analysis (currently under review) we found tDCS effects to be statistically significant, with the effect size of similar magnitude than observed in clinical trials ${ }^{54}$. Nonetheless, further randomized clinical trials are necessary and, in fact, several trials are being currently performed worldwide - according to clinicaltrials.org (assessed online on November 27, 2013), there are 15 randomized clinical trials evaluating the clinical efficacy of tDCS in depression. Therefore, in the next years a definite answer regarding tDCS clinical efficacy is expected.

\section{Conclusion}

Transcranial direct current stimulation is a promising somatic therapy for the treatment of major depression. Low cost, easiness of use and absence of severe adverse effects are its main advantages. Further, the development of "home-use" tDCS devices might help in overcoming one of the main caveats in non-invasive neuromodulatory therapies, which is the need to perform daily visits to the clinic to have the stimulation sessions delivered. Although initial tDCS trials displayed mixed findings; recent, larger trials showed that tDCS was effective in depression treatment. Future ongoing studies will provide a definite answer regarding the role of tDCS in the therapeutic arsenal of depression.

\section{Acknowledgments}

ARB receives research grants from FAPESP (2012/20911-5), NARSAD (2013 Young Investigator) and CNPq.

\section{References}

1. Largus S. De compositionibus medicamentorum. Paris; 1529.

2. Brunoni AR, Nitsche MA, Bolognini N, Bikson M, Wagner T, Merabet $\mathrm{L}$, et al. Clinical research with transcranial direct current stimulation (tDCS): Challenges and future directions. Brain Stimul. 2012;5:175-95.

3. Lippold OC, Redfearn JW. Mental changes resulting from the passage of small direct currents through the human brain. Br J Psychiatry. 1964;110:768-72.

4. Carney MW, Cashman MD, Sheffield BF. Polarization in depression. Br J Psychiatry. 1970;117:474-5.

5. Nias DK, Shapiro MB. The effects of small electrical currents upon depressive symptoms. Br J Psychiatry. 1974;125:414-5.

6. Brunoni AR, Tadini L, Fregni F. Changes in clinical trials methodology over time: a systematic review of six decades of research in psychopharmacology. PLoS One. 2010;5:e9479.

7. Priori A, Berardelli A, Rona S, Accornero N, Manfredi M. Polarization of the human motor cortex through the scalp. Neuroreport. 1998;9:2257-60.

8. Nitsche MA, Paulus W. Excitability changes induced in the human motor cortex by weak transcranial direct current stimulation. J Physiol. 2000;527 Pt 3:633-9.

9. Datta A, Bansal V, Diaz J, Patel J, Reato D, Bikson M. Gyri-precise head model of transcranial direct current stimulation: improved spatial focality using a ring electrode versus conventional rectangular pad. Brain Stimul. 2009;2:201-7.

10. Purpura DP, McMurtry JG. Intracellular activities and evoked potential changes during polarization of motor cortex. J Neurophysiol. 1965;28:166-85.

11. Stagg CJ, Nitsche MA. Physiological basis of transcranial direct current stimulation. Neuroscientist. 2011;17:37-53.

12. Brunoni AR, Amadera J, Berbel B, Volz MS, Rizzerio BG, Fregni F. A systematic review on reporting and assessment of adverse effects associated with transcranial direct current stimulation. Int J Neuropsychopharmacol. 2011;14:1133-45.

13. Palm U, Keeser D, Schiller C, Fintescu Z, Nitsche M, Reisinger E, et al. Skin lesions after treatment with transcranial direct current stimulation (tDCS). Brain Stimul. 2008;1:386-7.

14. Liebetanz D, Koch R, Mayenfels S, Konig F, Paulus W, Nitsche MA. Safety limits of cathodal transcranial direct current stimulation in rats. Clin Neurophysiol. 2009;120:1161-7.

15. Tadini L, El-Nazer R, Brunoni AR, Williams J, Carvas M, Boggio P, et al. Cognitive, mood, and electroencephalographic effects of noninvasive cortical stimulation with weak electrical currents. J ECT. 2011;27:134-40.

16. Brunoni AR, Kemp AH, Dantas EM, et al. Heart rate variability is a trait marker of major depressive disorder: evidence from the sertraline vs. electric current therapy to treat depression clinical study. Int J Neuropsychopharmacol. 2013;16(9):1937-49. 
17. Vandermeeren Y, Jamart J, Ossemann M. Effect of tDCS with an extracephalic reference electrode on cardio-respiratory and autonomic functions. BMC Neuroscience. 2010;11:38.

18. Palm U, Reisinger E, Keeser D, Kuo MF, Pogarell O, Leicht G, et al. Evaluation of sham transcranial direct current stimulation for randomized, placebo-controlled clinical trials. Brain Stimul. 2013;6:690-5.

19. Brunoni AR, Schestatsky P, Lotufo PA, Bensenor IM, Fregni F. Comparison of blinding effectiveness between sham tDCS and placebo sertraline in a 6-week major depression randomized clinical trial. Clin Neurophysiol. 2014;125(2):298-305.

20. Gandiga PC, Hummel FC, Cohen LG. Transcranial DC stimulation (tDCS): a tool for double-blind sham-controlled clinical studies in brain stimulation. Clin Neurophysiol. 2006;117:845-50.

21. Kuo MF, Paulus W, Nitsche MA. Therapeutic effects of non-invasive brain stimulation with direct currents (tDCS) in neuropsychiatric diseases. Neuroimage. 2014;85 Pt 3:948-60.

22. Grimm S, Beck J, Schuepbach D, Hell D, Boesiger P, Bermpohl F, et al. Imbalance between left and right dorsolateral prefrontal cortex in major depression is linked to negative emotional judgment: an fMRI study in severe major depressive disorder. Biol Psychiatry. 2008;63:369-76.

23. Mayberg HS, Brannan SK, Tekell JL, Silva JA, Mahurin RK, McGinnis $S$, et al. Regional metabolic effects of fluoxetine in major depression: serial changes and relationship to clinical response. Biol Psychiatry. 2000;48:830-43.

24. Oliveira JF, Zanão TA, Valiengo L, Lotufo PA, Benseñor IM, Fregni F, et al. Acute working memory improvement after tDCS in antidepressant-free patients with major depressive disorder. Neurosci Lett. 2013;537:60-4.

25. Brunoni AR, Vanderhasselt MA, Boggio PS, Fregni F, Dantas EM, Mill JG, et al. Polarity- and valence-dependent effects of prefrontal transcranial direct current stimulation on heart rate variability and salivary cortisol. Psychoneuroendocrinology. 2013;38:58-66.

26. Boggio PS, Bermpohl F, Vergara AO, Muniz AL, Nahas FH, Leme PB, et al. Go-no-go task performance improvement after anodal transcranial DC stimulation of the left dorsolateral prefrontal cortex in major depression. J Affect Disord. 2007;101:91-8.

27. Schutter DJ. Antidepressant efficacy of high-frequency transcranial magnetic stimulation over the left dorsolateral prefrontal cortex in double-blind sham-controlled designs: a meta-analysis. Psychol Med. 2009;39:65-75.

28. Schutter DJ. Quantitative review of the efficacy of slow-frequency magnetic brain stimulation in major depressive disorder. Psychol Med. 2010;40:1789-95.

29. Rigonatti SP, Boggio PS, Myczkowski ML, Otta E, Fiquer JT, Ribeiro RB, et al. Transcranial direct stimulation and fluoxetine for the treatment of depression. Eur Psychiatry. 2008;23:74-6.

30. Ferrucci R, Bortolomasi M, Vergari M, Tadini L, Salvoro B, Giacopuzzi $\mathrm{M}$, et al. Transcranial direct current stimulation in severe, drug-resistant major depression. J Affect Disord. 2009;118:215-9.

31. Ferrucci R, Bortolomasi M, Brunoni AR, et al. Comparative benefits of Transcranial Direct Current Stimulation (tDCS) treatment in patients with mild/moderate vs. severe depression. Clin Neuropsychiatry. 2009;6:246-51.

32. Brunoni AR, Ferrucci R, Bortolomasi M, Vergari M, Tadini L, Boggio PS, et al. Transcranial direct current stimulation (tDCS) in unipolar vs. bipolar depressive disorder. Prog Neuropsychopharmacol Biol Psychiatry. 2011;35:96-101.

33. Dell'Osso B, Zanoni S, Ferrucci R, Vergari M, Castellano F, D’Urso N, et al. Transcranial direct current stimulation for the outpatient treatment of poor-responder depressed patients. Eur Psychiatry. 2012;27:513-7.

34. Martin DM, Alonzo A, Mitchell PB, Sachdev P, Galvez V, Loo CK. Fronto-extracephalic transcranial direct current stimulation as a treatment for major depression: an open-label pilot study. J Affect Disord. 2011;134:459-63.

35. Brunoni AR, Ferrucci R, Bortolomasi M, Scelzo E, Boggio PS, Fregni F, et al. Interactions between transcranial direct current stimulation (tDCS) and pharmacological interventions in the major depressive episode: findings from a naturalistic study. Eur Psychiatry. 2013;28(6):356-61.

36. Fregni F, Boggio PS, Nitsche MA, Marcolin MA, Rigonatti SP, Pascual-Leone A. Treatment of major depression with transcranial direct current stimulation. Bipolar Disord. 2006;8:203-4.

37. Fregni F, Boggio PS, Nitsche MA, Rigonatti SP, Pascual-Leone A. Cognitive effects of repeated sessions of transcranial direct current stimulation in patients with depression. Depress Anxiety. 2006;23:482-4.

38. Boggio PS, Rigonatti SP, Ribeiro RB, Myczkowski ML, Nitsche MA, Pascual-Leone A, et al. A randomized, double-blind clinical trial on the efficacy of cortical direct current stimulation for the treatment of major depression. Int J Neuropsychopharmacol. 2008;11:249-54.

39. Loo CK, Sachdev P, Martin D, Pigot M, Alonzo A, Malhi GS, et al. A double-blind, sham-controlled trial of transcranial direct current stimulation for the treatment of depression. Int J Neuropsychopharmacol. 2010;13:61-9.

40. Palm U, Schiller C, Fintescu Z, Obermeier M, Keeser D, Reisinger E, et al. Transcranial direct current stimulation in treatment resistant depression: a randomized double-blind, placebo-controlled study. Brain Stimul. 2012;5:242-51.

41. Blumberger DM, Tran LC, Fitzgerald PB, Hoy KE, Daskalakis ZJ. A randomized double-blind sham-controlled study of transcranial direct current stimulation for treatment-resistant major depression. Front Psychiatry. 2012;3:74.

42. Loo CK, Alonzo A, Martin D, Mitchell PB, Galvez V, Sachdev P. Transcranial direct current stimulation for depression: 3-week, randomised, sham-controlled trial. Br J Psychiatry. 2012;200:52-9.

43. Brunoni AR, Valiengo L, Baccaro A, Zanão TA, de Oliveira JF, Goulart A, et al. The sertraline vs. electrical current therapy for treating depression clinical study: results from a factorial, randomized, controlled trial. JAMA Psychiatry. 2013;70:383-91.

44. Valiengo L, Benseñor IM, Goulart AC, de Oliveira JF, Zanao TA, Boggio PS, et al. The sertraline versus electrical current therapy for treating depression clinical study (SELECT-TDCS): results of the crossover and follow-up phases. Depress Anxiety. 2013;30:646-53.

45. Martin DM, Alonzo A, Ho KA, Player M, Mitchell PB, Sachdev P, et al. Continuation transcranial direct current stimulation for the prevention of relapse in major depression. J Affect Disord. 2013;144:274-8.

46. Baccaro A, Brunoni AR, Bensenor IM, Fregni F. Hypomanic episode in unipolar depression during transcranial direct current stimulation. Acta Neuropsychiatr. 2010;22:316-8.

47. Brunoni AR, Valiengo L, Zanao T, de Oliveira JF, Bensenor IM, Fregni F. Manic psychosis after sertraline and transcranial direct-current stimulation. J Neuropsychiatry Clin Neurosci. 2011;23:E4-5.

48. Arul-Anandam AP, Loo C, Mitchell P. Induction of hypomanic episode with transcranial direct current stimulation. J ECT. 2010;26:68-9.

49. Galvez V, Alonzo A, Martin D, Mitchell PB, Sachdev P, Loo CK. Hypomania induction in a patient with bipolar II disorder by transcranial direct current stimulation (tDCS). J ECT. 2011;27:256-8.

50. Bueno VF, Brunoni AR, Boggio PS, Bensenor IM, Fregni F. Mood and cognitive effects of transcranial direct current stimulation in post-stroke depression. Neurocase. 2011;17:318-22.

51. Palm U, Keeser D, Schiller C, Fintescu Z, Reisinger E, Baghai TC, et al. Transcranial direct current stimulation in a patient with therapy-resistant major depression. World J Biol Psychiatry. 2009;10:632-5.

52. Kalu UG, Sexton CE, Loo CK, Ebmeier KP. Transcranial direct current stimulation in the treatment of major depression: a meta-analysis. Psychol Med. 2012;42:1791-800.

53. Berlim MT, Van den Eynde F, Daskalakis ZJ. Clinical utility of transcranial direct current stimulation (tDCS) for treating major depression: a systematic review and meta-analysis of randomized, double-blind and sham-controlled trials. J Psychiatr Res. 2013;47:1-7.

54. Kirsch I, Deacon BJ, Huedo-Medina TB, Scoboria A, Moore TJ, Johnson BT. Initial severity and antidepressant benefits: a meta-analysis of data submitted to the Food and Drug Administration. PLoS Med. 2008;5:e45. 
55. Valiengo LC, Bensenor IM, Lotufo PA, Fraguas R Jr., Brunoni AR. Transcranial direct current stimulation and repetitive transcranial magnetic stimulation in consultation-liaison psychiatry. Braz J Med Biol Res. 2013;46:815-23.

56. Nitsche MA, Kuo MF, Karrasch R, Wachter B, Liebetanz D, Paulus W. Serotonin affects transcranial direct current-induced neuroplasticity in humans. Biol Psychiatry. 2009;66:503-8.

57. Brunoni AR, Kemp AH, Shiozawa P, Cordeiro Q, Valiengo LC, Goulart $\mathrm{AC}$, et al. Impact of 5-HTTLPR and BDNF polymorphisms on response to sertraline versus transcranial direct current stimulation: Implications for the serotonergic system. Eur Neuropsychopharmacol. 2013;23(11):1530-40.

58. Brunoni AR, Junior RF, Kemp AH, Lotufo PA, Bensenor IM, Fregni F. Differential improvement in depressive symptoms for tDCS alone and combined with pharmacotherapy: an exploratory analysis from the Sertraline vs. Electrical Current Therapy for Treating Depression Clinical Study. Int J Neuropsychopharmacol. 2014;17(1):53-61. 